\title{
TINGKAT PARTISIPASI MASYARAKAT TERHADAP KELESTARIAN EKOSISTEM MANGROVE DI DESA UWEDIKAN KECAMATAN LUWUK TIMUR
}

\author{
Sri Sukari Agustina, dan Aonurofiq \\ Staf Pengajar Fakultas Perikanan Universitas Muhammadiyah Luwuk
}

\begin{abstract}
The purpose of this study was to analyze activities applied in community participatory development, and to analyze influencing community participation factors in mangrove ecosystem preserve at Uwedikan Village East Luwuk District Banggai Regency. The statistical population includes stake holders from Fisheries and Marine Department Banggai Regency and coastal community Uwedikan Villages East Luwuk District includes PNS, farmer, entrepreneur, trader, and fish farmer and fisherman. Available respondents were selected based cluster random sampling. For to known correlation between dependent variable and independent variable to used regression analize. The result of research showed that coastal community participation level Uwedikan Villages based age factor, education, job, income and long live factor including in very highly criteria (76\%). From the result double linier regression analize as all age factor, education, job, income and long live factor had founded Adjusted $R^{2}$ value was 0,090, it means $9 \%$ participation level had influenced by the fifth independent variable, while the part of $91 \%$ explanationed by other variables out of the models.
\end{abstract}

Key words: mangrove, participation

\section{PENDAHULUAN}

Salah satu ekosistem pesisir dan laut yang merupakan komponen yang paling banyak berperan dalam menyeimbangkan kualitas lingkungan dan menetralisir bahan-bahan pencemar adalah ekosistem mangrove. Ekosistem mangrove mempunyai fungsi ekologi yang penting, seperti peredam gelombang dan angin, pelindung pantai dari abrasi, penahan lumpur dan penangkap sedimen yang diangkut oleh aliran air, sebagai daerah asuhan dan tempat mencari makan serta merupakan tempat pemijahan bermacam-macam biota perairan, sebagai penyubur perairan karena menghasilkan detritus dari seresah daun yang diuraikan oleh bakteri menjadi zat hara (Bengen, 2004). Selain itu produk dari mangrove dapat dihasilkan baik secara langsung ataupun tidak langsung sebagai kayu bakar, bahan bangunan, keperluan rumah tangga/perkakas, bahan kertas, bahan tekstil, alat perikanan, pupuk pertanian dan obat-obatan (Noor, Khazali dan Suryadiputra, 1999).

Ekosistem mangrove merupakan salah satu sumberdaya pesisir yang mengalami tingkat degradasi cukup tinggi akibat pola pemanfaatan yang cenderung tidak memperhatikan aspek kelestarian. Tingginya tingkat degradasi ekosistem mangrove dan mengingat potensialnya sumberdaya ini untuk menunjang kesejahteraan masyarakat dan produktivitas lingkungan sekitarnya, maka upaya pengelolaan dan pelestarian mangrove selayaknya diperhatikan dalam pembangunan wilayah pesisir di Desa Uwedikan Kecamatan Luwuk Timur Kabupaten Banggai. Salah satu upaya dalam menjaga kelestarian ekosistem mangrove adalah meningkatkan partisipasi masyarakat dan Pemerintah Daerah terhadap kelestarian ekosistem mangrove.

Penelitian ini bertujuan untuk menganalisis kegiatan-kegiatan yang digunakan di dalam pengembangan dan menganalisis faktor-faktor yang mempengaruhi partisipasi masyarakat dalam melestarikan ekosistem mangrove di Desa Uwedikan Kecamatan Luwuk Timur Kabupaten Banggai. Sedangkan manfaat dari penelitian ini adalah sebagai pijakan rekomendasi bagi Pemerintah Kabupaten Banggai dalam mengembangkan pengelolaan kawasan pesisir khususnya dalam melestarikan ekosistem mangrove. 


\section{METODOLOGI PENELITIAN}

Penelitian ini dilaksanakan pada bulan Agustus sampai dengan bulan September 2010 dengan lokasi penelitian Desa Uwedikan Kecamatan Luwuk Timur Kabupaten Banggai. Metode yang digunakan dalam penelitian yaitu metode survei. Populasi dalam penelitian adalah stake holder dari Dinas Kelautan dan Perikanan Kabupaten Banggai dan masyarakat pesisir Desa Uwedikan. yang bekerja sebagai pedagang, wiraswasta, petani, PNS, dan nelayan. Sampel yang dipilih dengan metode cluster random sampling dimana pengambilan sampel dilakukan melalui tahapan yaitu populasi sampling yang terdiri dari berbagai kelompok pekerjaan dan selanjutnya sampel yang diambil yaitu pedagang, wiraswasta, petani, PNS, dan nelayan, pemilihan responden dalam setiap kelompok dilakukan secara random. Jumlah responden total yang diambil 50 jiwa terdiri dari pedagang, wiraswasta, petani, PNS, dan nelayan.

Pengumpulan data dilakukan dengan menggunakan instrumen kuesioner, untuk memperoleh data yang valid dan reliabel dilakukan uji validitas dan reliabilitas (Ghozali, 2006). Validitasnya menunjukkan 8 pertanyaan partisipasi mempunyai probabilitas korelasi [sig. (2tailed)] sebesar $0,000<0,05$ maka sesuai kriteria, 8 pertanyaan partisipasi adalah valid. Reliabilitas kuesioner partisipasi mempunyai nilai koefisien reliabilitas 0,726 >0,60, maka angket partisipasi memiliki tingkat reliabilitas yang baik. Variabel penelitiannya yaitu variabel bebas (dependent) yaitu partisipasi dan variabel terikat (independent) yaitu usia, pendidikan, pekerjaan, penghasilan, dan lama tinggal. Data primer pada penelitian ini dilakukan dengan wawancara dibantu dengan kuesioner serta dengan melakukan observasi. Data sekunder berasal dari monografi desa.

Pengolahan data menggunakan bantuan komputer program SPSS (Statistical Product and Service Solution). Pengujian persyaratan analisis perlu dilakukan sebelum data dianalisis lebih lanjut dilakukan dengan uji normalitas. Teknik analisis data untuk faktor-faktor yang mempengaruhi partisipasi diukur dengan analisis regresi ganda. Pada analisis yang memakai regresi untuk memperoleh hasil yang baik, maka perlu dilakukan uji asumsi klasik yaitu koefisien determinasi $\left(\mathrm{R}^{2}\right)$, uji koefisien regresi secara serentak ( $F$-test), uji koefisien regresi secara individual (t-test) (Gujarati, 1995), uji normalitas, uji heteroskedastisitas, uji autokorelasi dan uji multikolinearitas (Ghozali, 2006).

\section{HASIL DAN PEMBAHASAN}

Tingkat Partisipasi dengan menggunakan uji Kolmogorov-Smirnov (K-S) menunjukkan nilai probabilitas signifikansi:

- Variabel usia 0,30>0,005, variabel pekerjaan 0,042>0,005, variabel lama tinggal 0,896> 0,005 , variabel partisipasi $0,256>0,005$ berarti ke empat variabel terdistribusi normal.

- Variabel pendidikan dan variabel penghasilan $0,000<0,005$ berarti kedua variabel terdistribusi tidak normal.

Tabel 1. Tingkat partisipasi PNS, petani, nelayan, wiraswasta, dan pedagang secara umum

\begin{tabular}{|c|l|c|c|}
\hline \multirow{2}{*}{ No. } & \multirow{2}{*}{ Kriteria } & \multicolumn{2}{|c|}{ Partisipasi } \\
\cline { 3 - 4 } & & $\sum \mathrm{R}$ & $\%$ \\
\hline 1. & Sangat Tinggi & 37 & 76 \\
\hline 2. & Tinggi & 8 & 10 \\
\hline 3. & Cukup & 2 & 4 \\
\hline 4. & Rendah & 3 & 6 \\
\hline 5. & Sangat Rendah & 2 & 4 \\
\hline & Jumlah & 50 & 100 \\
\hline
\end{tabular}

Sumber: Data primer diolah (2010)

Hasil wawancara maupun jawaban responden melalui kuesioner (Tabel 1) menunjukkan bahwa secara umum sebagian besar, tingkat partisipasi terhadap kelestarian ekosistem mangrove dapat dikategorikan sangat tinggi yaitu tingkat partisipasi sebesar $76 \%$. Selanjutnya 
berdasarkan hasil penelitian diketahui bahwa tingkat partisipasi tinggi dan sangat tinggi terbesar pada usia 15-64 tahun dan > 64 tahun. Hal ini berarti terdapat kecenderungan semakin tua usia seseorang semakin tinggi tingkat partisipasinya. Tingkat partisipasi sangat tinggi terbesar pada pendidikan SMA dan terkecil Akademi/PT. Tingkat partisipasi sangat rendah terbesar SD dan SMP. Hal ini berarti semakin tinggi pendidikan semakin tinggi partisipasinya. Tingkat partisipasi sangat tinggi terbesar pada penghasilan >Rp.1.550.000 sedangkan tingkat partisipasi sangat rendah dan rendah pada penghasilan <Rp.777.500. Hal ini berarti semakin tinggi penghasilan semakin tinggi tingkat partisipasinya. Tingkat partisipasi sangat tinggi terbesar pada lama tinggal 16-20 tahun dan $>20$ tahun sedangkan tingkat partisipasi sangat rendah terbesar pada lama tinggal $0-5$ tahun. Hal ini berarti terdapat kecenderungan semakin lama tinggal semakin tinggi partisipasinya.

Keterlibatan masyarakat pesisir dalam perencanaan dapat dilihat dari turut serta menghadiri rapat-rapat persiapan, memberikan tanggapan dan usul mengenai gagasan yang ada, ikut menyetujui dan merumuskan rencana yang ada. Oleh karena itu keterlibatan masyarakat pesisir perlu dilibatkan sejak awal program, maka akan timbul tanggung jawab dan rasa memiliki. Keikutsertaan masyarakat pesisir dalam pelaksanaan dapat berbentuk ikut serta melaksanakan apa yang telah diputuskan bersama dengan memberikan sumbangan berupa uang, material maupun tenaga. Partisipasi masyarakat pesisir dalam pengawasan dilakukan dengan secara aktif mengikuti perkembangan pelaksanaan kegiatan melestarikan ekosistem mangrove, ikut menegur, memberikan peringatan terdapat mereka yang melanggar. Partisipasi masyarakat dalam pengawasan kegiatan tersebut dapat dilihat sejauh mana masyarakat pesisir ikut mengawasi dan mengamati jalannya kegiatan, apakah masyarakat menyampaikan keberatan atau kritik terhadap penyimpangan yang ada, apakah masyarakat pesisir melakukan teguran terhadap hal-hal yang salah.

Menurut Rahardjo (1983), partisipasi diartikan sebagai upaya peran serta masyarakat dalam suatu kegiatan baik dalam bentuk pernyataan maupun kegiatan. Kegiatan melestarikan ekosistem mangrove di Desa Uwedikan yang menuntut partisipasi masyarakatnya merupakan pengelolaan sumberdaya laut yang berbasis masyarakat (community based management) yang mengandung arti keterlibatan langsung masyarakat dalam mengelola sumberdaya alam di suatu kawasan. Mengelola mengandung arti masyarakat ikut memikirkan, memformulasikan, merencanakan, mengimplemetasikan, mengevaluasi maupun memonitorinya, sesuatu yang menjadi kebutuhannya. Beberapa pengelolaan berbasis masyarakat (community based management) telah berhasil mengelola sumberdaya secara lestari (Ruddle et al., 1992). Hidayati (1999) dalam Khazali et al. (2002), salah satu langkah yang dapat dilakukan agar masyarakat dapat berpartisipasi dalam pengelolaan berbasis masyarakat adalah melalui pemberdayaan masyarakat dengan memperhatikan: akses informasi, akses pengawasan, penegakan dan perlindungan hukum, kesadaran masyarakat akan arti dan nilai sumberdaya ekosistem, partisipasi masyarakat dalam menjaga, mengelola dan melestarikan sumberdaya.

Persamaan analisis regresi linier berganda untuk mengetahui pengaruh variabel independen (usia, pendidikan, pekerjaan, penghasilan, dan lama tinggal) terhadap variabel dependen (partisipasi masyarakat) diperoleh persamaan regresi, yaitu:

$$
Y=16,552+0,024 X_{1}+0,610 X_{2}+0,426 X_{3}+1,827 E-6 X_{4}+0,39 X_{5}
$$

Hasil analisis $t$ test (Uji Parsial) (X1 tingkat probabilitas 0,700, X2 tingkat probabilitas 0,441, X3 tingkat probabilitas 0,524, X4 tingkat probabilitas 0,074 dan X5 tingkat probabilitas 0,371) dan uji F (Uji Simultan) didapat F hitung sebesar 1,971 dengan tingkat probabilitas 0,102 (non signifikan). Berdasarkan hal tersebut dapat diketahui bahwa variabel usia, pekerjaan, pendidikan, penghasilan dan lama tinggal tidak memberikan pengaruh yang signifikan terhadap partisipasi masyarakat. Hal ini diperkuat dengan hasil analisis nilai koefisien determinasi yang disesuaikan (adjusted $\mathrm{R}^{2}$ ) adalah 0,090 artinya 9\% tingkat partisipasi dipengaruhi oleh kelima variabel independen, sedangkan sisanya $91 \%$ dijelaskan oleh variabel lainnya di luar model. 


\section{KESIMPULAN}

Berdasarkan hasil penelitian dan pembahasan mengenai tingkat partisipasi masyarakat terhadap kelestarian ekosistem mangrove di Desa Uwedikan Kecamatan Luwuk Timur dapat disimpulkan :

1. Tingkat partisipasi masyarakat pesisir Desa Uwedikan berdasarkan faktor usia, pendidikan, pekerjaan, penghasilan dan lama tinggal rata-rata termasuk dalam kriteria sangat tinggi $(76 \%)$.

2. Dari hasil analisis regresi linier berganda secara keseluruhan faktor usia, pendidikan, pekerjaan, penghasilan dan lama tinggal didapatkan nilai Adjusted $\mathrm{R}^{2}$ adalah 0,090 , yang berarti hanya $9 \%$ tingkat partisipasi dipengaruhi oleh kelima variabel independen tersebut, sedangkan sisanya $91 \%$ dijelaskan oleh variabel lainnya di luar model.

\section{SARAN}

Merekomendasikan kepada Pemerintah Kabupaten Banggai khususnya Dinas Kelautan dan Perikanan terhadap kebijakan yang bisa ditempuh agar sumberdaya kegiatan menjaga kelestarian ekosistem mangrove berkelanjutan antara lain:

a. Kebijakan sosialisasi kegiatan larangan penebangan mangrove,

b. Kebijakan pemanfaatan sumberdaya laut yang ramah lingkungan.

\section{UCAPAN TERIMA KASIH}

Pada kesempatan ini penulis mengucapkan terima kasih kepada Bapak Moh. Gifari Sono, ST., MM selaku Ketua LITBANG Unismuh Luwuk, Bapak Ir. H. Rusdi Rachmad selaku Kepala DISLUTKAN Kabupaten Banggai, Bapak Lapulo Masiri selaku Kepala Desa beserta masyarakat Desa Uwedikan Kecamatan Luwuk Timur Kabupaten Banggai yang telah banyak membantu dalam pelaksanaan penelitian ini.

\section{DAFTAR PUSTAKA}

Bengen, D. G. 2004. Pedoman Tehnis Pengelolaan Ekosistem Mangrove. Pusat Kajian Pesisir dan Lautan. IPB. Bogor.

Currie, D. R. \& Parry, G. D., 1996. Effects of Scallop Dredging on a Soft Bottom Sediment Community: A Large-Scale Experimental Study. Marine Ecology Progress Series. 134: $131-150$.

Ghozali, I. 2006. Aplikasi Analisis Multivariate dengan Program SPSS. Badan Penerbit Universitas Diponegoro. Semarang.

Gujarati Damondar. 1999. Ekonometrika Dasar. Terjemahan Sumarno Zain. Erlangga. Jakarta.

Khazali, M., Bengen, D.G., dan Nikijuluw, V. P. H. 2002. Kajian Partisipasi Masyarakat dalam Pengelolaan Mangrove (Studi Kasus di Desa Karangsong, Kecamatan Indramayu, Kabupaten Indramayu, Jawa Barat). Jurnal Pesisir \& Lautan. Vol. 4 No. 3. Hal. 45-51.

Nazir, M. 2005. Metode Penelitian. Cetakan Keenam. Ghalia Indonesia. Jakarta.

Noor YR, Khazali M, Suryadiputra INN. 1999. Guide to Introduction of Mangrove in Indonesia. Wetlands International Indonesia Programme. Bogor.

Rahardjo, Dawam. 1983. Esei-esei Ekonomi Politik. Jakarta; LP3ES.

Ruddle, K., Hviding. E. and Johannes. 1992. Marine Resource Management in the Context of Customary Tenure. Marine Resource Economics, 7: 249-273.

Sekaran, U. 1992. Research Methods for Business: A Skill Building Approach. John Willey \& Sons, Inc. New York.

Steel, R. G. D. dan J. H. Torrie. 1993. Prisip dan Prosedur Statistika, Suatu Pendekatan Biometrik. Gramedia Pustaka Utama. Jakarta. 